\author{
Atos de Pesquisa em Educação - ISSN 1809-0354 \\ Blumenau - vol. 11, n. 2, p.374-395 ago./nov. 2016 \\ DOI: http://dx.doi.org/10.7867/1809-0354.2016v11n2p374-395
}

\title{
POLÍTICAS PÚBLICAS E EDUCAÇÃO ESPECIAL: UMA ANÁLISE SOBRE O AUTISMO
}

PUBLIC POLICIES AND SPECIAL EDUCATION: AN ANALYSIS ON AUTISM

\author{
GUARESCHI, Taís \\ tais.guareschi@gmail.com \\ UFSM - Universidade Federal de Santa Maria \\ ALVES, Marcia Doralina \\ marciapsico@terra.com.br \\ UFSM - Universidade Federal de Santa Maria \\ NAUJORKS, Maria Inês \\ minau1990@gmail.com \\ UFSM - Universidade Federal de Santa Maria
}

RESUMO: O campo da Educação Especial tem sofrido diversas modificações em relação à definição dos sujeitos a quem essa modalidade se destina. Este artigo visa analisar como o autismo foi sendo, ao longo do tempo, nomeado e concebido nesse campo em políticas públicas nacionais e documentos publicados pelo Ministério da Educação (MEC) e pelo Instituto Nacional de Estudos e Pesquisas Educacionais Anísio Teixeira (INEP) no Brasil. A metodologia de investigação utilizada é a pesquisa documental, tomando como materialidade de análise documentos publicados de 1994 a 2015. A análise evidenciou constantes alterações nas formas de nomeação, abordagem do autismo de forma pouco clara e discurso médico psiquiátrico sendo tomado como referência em documentos mais recentes.

PALAVRAS-CHAVE: Autismo. Educação Especial. Educação Inclusiva. Políticas Públicas.

ABSTRACT: The area of Special Education has undergone a great number of changes in relation to the definition of the subjects to whom this area is addressed to. This paper aims at analyzing how autism, over the years, has been named and conceived in the area of national public policies documents published by the Ministry of Education (MEC) and The National Institute for Educational Research and Study Anísio Teixeira (INEP) in Brazil. The methodology for investigation used in this paper is documental research, taking as material for analysis documents published between 1994 and 2015. The analysis showed constant alterations in the forms of naming, approach to autism in a not very clear way, and medical psychiatric discourse being used as a reference in the most recent documents.

KEYWORDS: Autism. Special Education. Inclusive Education. Public Policies.

\section{INTRODUÇÃO}




\section{Atos de Pesquisa em Educação - ISSN 1809-0354 \\ Blumenau - vol. 11, n. 2, p.374-395 ago./nov. 2016 \\ DOI: http://dx.doi.org/10.7867/1809-0354.2016v11n2p374-395}

O campo da Educação Especial tem sofrido diversas modificações nas duas últimas décadas no que diz respeito às políticas públicas que orientam essa modalidade de ensino. Essas mudanças referem-se às formas de nomear e definir os sujeitos a quem essa modalidade se destina e à forma de organização da escolarização desses alunos. Nesse sentido, desde a década de 1990, foi intensificado o movimento de inclusão escolar, o que ocasionou uma série de publicações internacionais, por conseguinte, no Brasil, com o objetivo de assegurar direitos de acesso e permanência à escola comum.

A inclusão escolar tornou-se um imperativo legitimado no discurso da educação por meio de políticas públicas. Esses documentos orientam a organização e as práticas escolares das instituições de ensino. Dessa forma, é relevante olhar para o que enunciam, uma vez que possuem ampla circulação e seu discurso reverbera nas escolas.

Tendo em vista esse contexto, o objetivo deste artigo é analisar o modo como os alunos com autismo foram inscritos, designados e descritos em políticas públicas nacionais e documentos publicados pelo Ministério da Educação (MEC) e pelo Instituto Nacional de Estudos e Pesquisas Educacionais Anísio Teixeira (INEP), desde o ano de 1994. Esse ano é adotado como referência por ser o ano de publicação da Declaração de Salamanca, documento internacional que ratifica o compromisso da educação para todos e afirma que as escolas devem acolher todas as crianças, "independentemente de suas condições físicas, intelectuais, sociais, emocionais, linguísticas ou outras" (BRASIL, 1994a, p. 3). Esse documento, considerado marco da Educação Especial, impulsionou a ideia de educação inclusiva. Além disso, nesse mesmo ano, foi promulgada a Política Nacional de Educação Especial com vistas a garantir o atendimento educacional de alunos com necessidades educacionais especiais.

Sendo assim, utilizamos como metodologia de investigação a pesquisa documental, tomando como materialidade de análise políticas nacionais brasileiras, documentos orientadores do MEC e o Caderno de Instruções do Censo Escolar, publicados de 1994 a 2015. Para desenvolver a análise, inicialmente, situaremos as terminologias utilizadas nos documentos da Educação Especial e em quais 


\section{Atos de Pesquisa em Educação - ISSN 1809-0354 \\ Blumenau - vol. 11, n. 2, p.374-395 ago./nov. 2016 \\ DOI: http://dx.doi.org/10.7867/1809-0354.2016v11n2p374-395}

referenciais essas definições foram embasadas. Em seguida, analisaremos documentos do campo da Educação Especial que fazem referência aos alunos com autismo, descrevendo-os e abordando sua escolarização.

\section{OS MANUAIS MÉDICOS DE CLASSIFICAÇÃO: BASES PARA A DESIGNAÇÃO E DESCRIÇÃO DOS ALUNOS COM AUTISMO NOS DOCUMENTOS DA EDUCAÇÃO ESPECIAL}

A análise empreendida neste artigo, considerando o recorte temporal especificado, permite situar três formas de designação dos alunos com autismo nos documentos da Educação Especial desde 1994. A primeira terminologia a ser considerada, adotada pelos órgãos oficiais do Ministério da Educação, é condutas típicas. Essa categoria abrangia uma gama bastante ampla e diversa de sujeitos, dentre eles, os alunos com autismo, conforme discutiremos a partir da análise dos documentos. Essa nomenclatura foi proposta por um grupo de trabalho na elaboração da Política Nacional de Educação Especial, publicada em 1994, e não constava em manuais de classificação ou diagnósticos de transtornos mentais utilizados como referência no Brasil (ROCHA; COSTA, 2009). A expressão condutas típicas fazia referência a alunos cujos comportamentos considerados inadequados ocasionavam dificuldades de adaptação escolar e de relacionamento.

A segunda forma de designação, adotada a partir da promulgação da Política Nacional de Educação Especial na Perspectiva da Educação Inclusiva, em 2008, foi transtornos globais do desenvolvimento, dentre os quais figura o autismo. A partir da publicação dessa política os documentos passaram a utilizar o referencial do campo médico, especificamente dos transtornos mentais, para designar os alunos com autismo como público-alvo da Educação Especial, o que não acontecia até então.

Dessa forma, os manuais médicos DSM (Manual Diagnóstico e Estatístico de Transtornos Mentais), organizado pela Associação Americana de Psiquiatria e a Classificação de Transtornos Mentais e de Comportamento da $\operatorname{CID}^{1}-10$, elaborada pela Organização Mundial da Saúde (OMS), orientam as nomeações e as definições

\footnotetext{
${ }^{1}$ Classificação Internacional de Doenças (ORGANIZAÇÃO MUNDIAL DA SAÚDE, 1993).
} 


\section{Atos de Pesquisa em Educação - ISSN 1809-0354 \\ Blumenau - vol. 11, n. 2, p.374-395 ago./nov. 2016 \\ DOI: http://dx.doi.org/10.7867/1809-0354.2016v11n2p374-395}

nos documentos. O DSM é um manual de ampla influência mundial utilizado como base para o diagnóstico de transtornos mentais por médicos de muitos países. Por sua vez, a CID-10 é uma classificação de referência em saúde mental no Brasil, utilizada, na maioria dos casos, nos diagnósticos dos alunos com autismo encaminhados às escolas.

Ao fazer referência aos sujeitos com transtornos globais do desenvolvimento, a Política Nacional de Educação Especial na Perspectiva da Educação Inclusiva (BRASIL, 2008a) inclui, nesse grupo, alunos com autismo clássico, síndromes do espectro do autismo e psicose infantil. A Resolução CNE/CEB no 4/2009, que delibera sobre quem são os alunos atendidos pela Educação Especial, elencou cinco categorias nos transtornos globais do desenvolvimento: síndrome de Rett, autismo clássico, síndrome de Asperger, transtorno desintegrativo da infância (psicoses) e transtornos invasivos sem outra especificação (BRASIL, 2009a).

A terminologia transtornos globais do desenvolvimento (DSM-IV-TR) apresenta variações, podendo ser chamada também como transtornos invasivos do desenvolvimento (CID-10). Isso porque ambos os termos são as traduções da expressão, em inglês, pervasive developmental disorders.

A terminologia transtornos globais do desenvolvimento, utilizada nos textos legais sobre a modalidade de ensino da Educação Especial, é uma classificação psiquiátrica do Manual de Diagnóstico e Estatística de Distúrbios Mentais (DSM-IVTR), da Associação Americana de Psiquiatria. Nele, encontram-se a classificação e a descrição fenomenológica das doenças mentais baseadas em concepções neurobiológicas. Em relação à descrição desse quadro, o DSM-IV-TR traz a seguinte definição:

Os Transtornos Globais do Desenvolvimento caracterizam-se por um comprometimento grave e global em diversas áreas do desenvolvimento: habilidades de interação social recíproca, habilidades de comunicação ou presença de estereotipias de comportamento, interesses e atividades (ASSOCIAÇÃO AMERICANA DE PSIQUIATRIA, 2002, p. 98).

A referida definição foi amplamente utilizada no meio científico, na tentativa de facilitar a comunicação entre os profissionais das diferentes áreas quando se 


\section{Atos de Pesquisa em Educação - ISSN 1809-0354 \\ Blumenau - vol. 11, n. 2, p.374-395 ago./nov. 2016 \\ DOI: http://dx.doi.org/10.7867/1809-0354.2016v11n2p374-395}

tratava de nomear os sujeitos com transtornos globais do desenvolvimento. Nessa descrição, é possível observar uma tríade de alterações: nas habilidades de interação social; nas habilidades de comunicação; e estereotipais de comportamento, interesses e atividades.

No DSM-IV-TR, estão incluídas as seguintes categorias nos transtornos globais do desenvolvimento: transtorno autista, transtorno de Rett, transtorno desintegrativo da infância, transtorno de Asperger e transtorno global do desenvolvimento sem outra especificação (incluindo o autismo atípico). Por sua vez, na Classificação de Transtornos Mentais e de Comportamento da CID-10, encontram-se inseridas oito categorias nos transtornos invasivos do desenvolvimento: autismo infantil, autismo atípico, síndrome de Rett, outro transtorno desintegrativo da infância, transtorno de hiperatividade associado ao retardo mental e movimentos estereotipados, síndrome de Asperger, outros transtornos invasivos do desenvolvimento e transtorno invasivo do desenvolvimento não especificado.

Se observarmos as categorias elencadas no início do texto, perceberemos que as políticas atuais de Educação Especial baseiam-se no DSM-IV-TR para se referir aos sujeitos com transtornos globais do desenvolvimento como seu públicoalvo, embora com pequenas diferenças na forma de nomear os quadros psicopatológicos.

No ano de 2013, o DSM-IV-TR foi substituído por uma nova edição, o DSM-5. Nessa edição, ocorreu a modificação da nomenclatura, passando a ser utilizada a terminologia transtorno do espectro autista, e a supressão das cinco categorias que figuravam entre os transtornos globais do desenvolvimento. A síndrome de Rett, com causa comprovadamente genética, foi retirada. Por sua vez, a síndrome de Asperger, o transtorno desintegrativo da infância e o transtorno global do desenvolvimento sem outra especificação "desaparecem sobre o grande guardachuva do espectro autístico" (SIBEMBERG, 2015, p. 98).

Portanto, no DSM-5, há somente uma denominação: transtorno do espectro autista, que está descrito dentre os Transtornos do Neurodesenvolvimento. De acordo com Sibemberg (2015, p. 98-99): 


\author{
Atos de Pesquisa em Educação - ISSN 1809-0354 \\ Blumenau - vol. 11, n. 2, p.374-395 ago./nov. 2016 \\ DOI: http://dx.doi.org/10.7867/1809-0354.2016v11n2p374-395
}

\begin{abstract}
O que antes era diagnóstico diferencial passou a ser catalogado numa mesma categoria, estando a diferenciação assinalada pela intensidade dos sintomas no comportamento repetitivo e estereotipado, bem como com os distúrbios da linguagem, agora associados à relação social recíproca.
\end{abstract}

Conforme esse manual, os sintomas do autismo podem ser percebidos antes de um ano de idade, ou seja, ainda na primeira infância, quando a criança começa a apresentar falta de interesse nas relações com o outro. Diferentemente do DSM-IVTR, que apresentava uma tríade de alterações nos transtornos globais do desenvolvimento, a nova versão do DSM traz uma díade de características do transtorno do espectro do autismo. Essa díade envolve prejuízos importantes e contínuos na comunicação social recíproca e na interação social, além de padrões restritos e repetitivos de comportamento, interesses ou atividades, conforme pode ser observado na definição do transtorno do espectro autista:

A. Déficits persistentes na comunicação social e na interação social em múltiplos contextos, conforme manifestado pelo que segue, atualmente ou por história prévia (...).

B. Padrões restritos e repetitivos de comportamento, interesses ou atividades, conforme manifestado por pelo menos dois dos seguintes, atualmente ou por história prévia (...).

C. Os sintomas devem estar presentes precocemente no período de desenvolvimento (mas podem não se tornar plenamente manifestos até que as demandas sociais excedam as capacidades limitadas ou podem ser mascarados por estratégias aprendidas mais tarde na vida).

D. Os sintomas causam prejuízo clinicamente significativo no funcionamento social, profissional ou em outras áreas importantes na vida do indivíduo no presente.

E. Essas perturbações não são mais bem explicadas por deficiência intelectual (transtorno do desenvolvimento intelectual) ou por atraso global do desenvolvimento. Deficiência intelectual ou transtorno do espectro autista costumam ser comórbidos; para fazer o diagnóstico da comorbidade de transtorno do espectro autista e deficiência intelectual, a comunicação social deve estar abaixo do esperado para o nível geral do desenvolvimento (ASSOCIAÇÃO AMERICANA DE PSIQUIATRIA, 2014, p. 50-51).

A previsão dessa modificação em relação à nomeação da categoria dos transtornos globais do desenvolvimento no DSM-V, edição que vinha sendo discutida já em 2012, produziu efeitos nos textos da Lei oㅜ 12.764, de 27 de dezembro de 2012, que "Institui a Política Nacional de Proteção dos Direitos da 


\section{Atos de Pesquisa em Educação - ISSN 1809-0354 \\ Blumenau - vol. 11, n. 2, p.374-395 ago./nov. 2016 \\ DOI: http://dx.doi.org/10.7867/1809-0354.2016v11n2p374-395}

Pessoa com Transtorno do Espectro Autista" (BRASIL, 2012), e da Nota Técnica ํㅡㄴ 24/2013/MEC/SECADI/DPEE, que orienta os sistemas de ensino para a implementação dessa lei (BRASIL, 2013a).

Assim, localizamos nos textos da Política Nacional de Proteção dos Direitos da Pessoa com Transtorno do Espectro Autista e da Nota Técnica no 24/2013/MEC/SECADI/DPEE, a terceira terminologia utilizada para nomear os alunos com autismo: transtorno do espectro autista.

\section{O OLHAR DOS DOCUMENTOS DA EDUCAÇÃO ESPECIAL PARA OS SUJEITOS COM AUTISMO}

Para compreendermos a forma como o autismo vem sendo incorporado e descrito nos últimos anos no campo da Educação Especial, realizamos a análise de documentos publicados pela extinta Secretaria de Educação Especial (SEESP) do MEC $^{2}$, de Cadernos de Instruções do Censo Escolar - Educacenso, produzidos pelo INEP de 2007 a 2015, e de uma nota técnica promulgada pela Secretaria de Educação Continuada, Alfabetização, Diversidade e Inclusão (SECADI) do MEC.

É interessante ressaltar que os alunos com autismo nem sempre figuraram claramente nos textos da Educação Especial. Porém, a partir da publicação da Política Nacional de Educação Especial na perspectiva da Educação Inclusiva (BRASIL 2008a), os dispositivos legais que se seguiram e os demais documentos orientadores passaram a tratar mais especificamente sobre esses sujeitos e sua escolarização.

A análise dos documentos será iniciada com a apreciação da Política Nacional de Educação Especial, publicada em 1994, documento que estabelece "um conjunto de objetivos destinados a garantir o atendimento educacional do alunado portador de necessidades especiais, cujo direito à igualdade de oportunidades nem sempre é respeitado" (BRASIL, 1994b, p. 7).

\footnotetext{
${ }^{2}$ A Secretaria de Educação Especial (SEESP) foi extinta no ano de 2011. Seus programas e suas ações estão vinculadas atualmente à Secretaria de Educação Continuada, Alfabetização, Diversidade e Inclusão (SECADI).
} 


\section{Atos de Pesquisa em Educação - ISSN 1809-0354 \\ Blumenau - vol. 11, n. 2, p.374-395 ago./nov. 2016 \\ DOI: http://dx.doi.org/10.7867/1809-0354.2016v11n2p374-395}

Ao tratar do alunado da Educação Especial, esse documento faz referência a alunos com deficiência (mental, visual, auditiva, física, múltipla), a alunos com condutas típicas e a alunos com altas habilidades (superdotados) (BRASIL, 1994a). No universo de alunos da Educação Especial, os sujeitos com autismo eram nomeados sob a expressão genérica de condutas típicas. A Política Nacional de Educação Especial define as condutas típicas como sendo:

Manifestações de comportamento típicas de portadores de síndromes e quadros psicológicos, neurológicos ou psiquiátricos que ocasionam atrasos no desenvolvimento e prejuízos no relacionamento social, em grau que requeira atendimento educacional especializado (BRASIL, 1994b, p.12).

Os alunos com condutas típicas eram considerados sujeitos que possuíam dificuldades de adaptação ao ambiente, apresentando comportamentos considerados inadequados, como, por exemplo, agressividade, alheamento e hiperatividade. Tais comportamentos estavam associados a dificuldades acentuadas de aprendizagem, que os levavam a necessitar dos serviços oferecidos pela Educação Especial.

Para continuar essa análise, elegemos a Resolução oㅡ CNE/CEB ํㅡㄴ 02, de 11 de setembro de 2001, que instituía as Diretrizes Nacionais para a Educação Especial na Educação Básica. Essa Resolução, em seu Artigo 5a, afirma que são considerados alunos com necessidades educacionais especiais, atendidos pela Educação Especial, os sujeitos que apresentarem:

I- Dificuldades acentuadas de aprendizagem ou limitações no processo de desenvolvimento que dificultem 0 acompanhamento das atividades curriculares, compreendidas em dois grupos:

a) Aquelas não vinculadas a uma causa orgânica específica;

b) Aquelas relacionadas a condições, disfunções, limitações ou deficiências;

II- $\quad$ Dificuldades de comunicação e sinalização diferenciadas dos demais alunos, demandando a utilização de linguagens e códigos aplicáveis;

III- Altas habilidades/superdotação, grande facilidade de aprendizagem que os leve a dominar rapidamente conceitos, procedimentos e atitudes (BRASIL, 2001, p. 2).

Dessa forma, essa resolução definia como alunos da Educação Especial esses três grupos: sujeitos com dificuldades acentuadas de aprendizagem; com 


\section{Atos de Pesquisa em Educação - ISSN 1809-0354 \\ Blumenau - vol. 11, n. 2, p.374-395 ago./nov. 2016 \\ DOI: http://dx.doi.org/10.7867/1809-0354.2016v11n2p374-395}

dificuldade de comunicação e sinalização; e com altas habilidades/superdotação. Nesse universo, os sujeitos com autismo figuravam entre os alunos com dificuldades acentuadas de aprendizagem. É possível observar uma modificação na forma de nomear os estudantes que seriam atendidos pela Educação Especial em relação à Política Nacional de Educação Especial (BRASIL, 1994b).

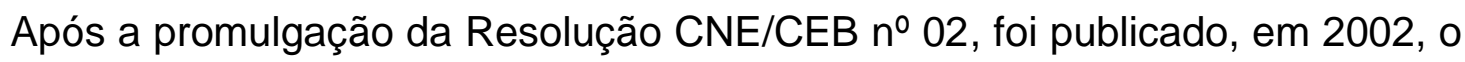
volume "Dificuldades acentuadas de aprendizagem, relacionadas a condutas típicas", do Projeto Escola Viva, o qual abordava a inclusão educacional desses alunos (BRASIL, 2002). Esse documento é intitulado com base nas novas definições da resolução, ou seja, utiliza a expressão dificuldades acentuadas de aprendizagem e dá ênfase ao trabalho com os alunos com condutas típicas, terminologia da política nacional.

Essa publicação esclarece que as condutas típicas podem ser identificadas quando os comportamentos considerados inadequados ou inconvenientes "[...] forem exibidos como padrão, por um continuado e extenso período de tempo [...]" (BRASIL, 2002, p. 9). Tais comportamentos, segundo o documento, podem ocasionar prejuízos para o próprio sujeito, para os outros e para as relações sociais.

Conforme a Resolução CNE/CEB oo 02 (2002), em alguns sujeitos é observado um padrão comportamental voltado para si próprio, como, por exemplo, automutilação, alheamento e recusa em falar ou manter contato visual. Há, ainda, sujeitos cujos comportamentos impróprios são voltados para o ambiente exterior, tais como agredir, gritar, roubar e mentir. Segundo as afirmações do texto, os alunos com condutas típicas não possuem, geralmente, comprometimento ou atraso intelectual; todavia, seu desempenho escolar está relacionado à intensidade e à frequência do padrão comportamental que apresentam.

Com base na apreciação desse documento, é possível constatarmos o quão ampla era expressão condutas típicas. Entre as definições apontadas até o presente notamos que algumas manifestações fazem parte do autismo. Ao analisarmos os comportamentos considerados inadequados, pertencentes às condutas típicas, e as manifestações do autismo, encontramos diversas características convergentes, embora no texto não seja citado o termo autismo. Por conseguinte, é possível 


\section{Atos de Pesquisa em Educação - ISSN 1809-0354 \\ Blumenau - vol. 11, n. 2, p.374-395 ago./nov. 2016 \\ DOI: http://dx.doi.org/10.7867/1809-0354.2016v11n2p374-395}

destacar características como o prejuízo no relacionamento social, a recusa em manter contato visual e a recusa em falar.

Acreditamos que, apesar de algumas dessas características assemelharemse nos dois conceitos (condutas típicas e autismo), não podemos tomá-las como padrão de conduta, uma vez que nem todos os sujeitos com autismo apresentam as mesmas manifestações. Cada sujeito se mostrará de forma singular e utilizará recursos próprios para encontrar saídas diante das dificuldades com relação ao mundo que o cerca. Alguns falam muito, ao passo que outros se recusam a verbalizar. Outros, ainda, tapam os ouvidos com as mãos, quando o som do ambiente é invasivo. Há também aqueles que se mostram indiferentes ao chamado das pessoas, parecendo não as escutar.

Em relação às condutas típicas mais usualmente descritas, são citados os distúrbios da atenção, a hiperatividade, a impulsividade, o alheamento $e$ agressividade física e/ou verbal. É importante considerarmos uma dessas condutas mencionadas que, dentre outras, parece referir-se claramente a manifestações do autismo: $o$ alheamento. Nesse quadro:

Há crianças que se esquivam, ou mesmo se recusam terminantemente a manter contato com outras pessoas, ou com qualquer outro aspecto do ambiente sociocultural no qual se encontram inseridas. [...] em sua manifestação mais severa, encontram-se crianças que não fazem contato com a realidade, parecendo desenvolver e viver em um mundo só seu, à parte da realidade (BRASIL, 2002, p. 14).

Para continuarmos a análise, destacamos um aspecto apontado logo no início do texto, quando é afirmado que a expressão condutas típicas refere-se a um grande número de comportamentos, o que dificultaria o consenso em sua definição. No que diz respeito ao autismo, acreditamos que um termo tão genérico quanto condutas típicas e sua concepção também tenham obstaculizado $\circ$ trabalho pedagógico da Educação Especial com esses sujeitos. A seguir, esclareceremos essa questão com base na apreciação do Documento Subsidiário à Política de Inclusão, publicado pela SEESP no ano de 2005. Nele, é abordada a problemática de se utilizar um termo tão amplo. 


\section{Atos de Pesquisa em Educação - ISSN 1809-0354 \\ Blumenau - vol. 11, n. 2, p.374-395 ago./nov. 2016 \\ DOI: http://dx.doi.org/10.7867/1809-0354.2016v11n2p374-395}

De acordo com o Documento subsidiário à política de inclusão (BRASIL, 2005 , p. 17) "sob este rótulo, encontramos comportamentos associados a quadros neurológicos, psicológicos e psiquiátricos complexos e persistentes". Compartilhamos da ideia de que o uso da expressão condutas típicas gera dois problemas importantes: a ênfase na conduta manifesta e a impossibilidade de identificar pontos importantes em quadros bastante diferenciados.

Em relação ao primeiro problema, quando, no trabalho pedagógico, damos ênfase à conduta manifesta, ou seja, aos comportamentos considerados inadequados, não levamos em conta a subjetividade de nosso aluno. Ao postularmos que o sujeito com condutas típicas apresenta comportamentos impróprios que precisam ser modificados, acabamos por produzir uma educação automatizada e sem sentido para o sujeito. Nessa perspectiva, reduzimos o aluno a uma determinada classe de pessoas que precisa ser adaptada na escola.

O segundo problema é o fato de a terminologia condutas típicas abranger "[...] uma diversidade muito grande de leituras diagnósticas, impossibilitando que sejam discriminados alguns importantes pontos referentes a cada uma delas" (BRASIL, 2005, p. 17). Na verdade, trata-se de um termo que possui um caráter inespecífico, abrangendo muitas possibilidades diagnósticas. Entendemos que há diferenças fundamentais em se trabalhar com crianças consideradas hiperativas ou com déficit de atenção e com crianças com autismo, por exemplo.

A fim de orientar os professores da Educação Infantil, em 2004, foi divulgado, pelo MEC, um volume que fazia parte de uma série de publicações nomeada "Saberes e práticas da inclusão", intitulado "Dificuldades acentuadas de aprendizagem - autismo". Observamos, no próprio título do documento, que a expressão dificuldades acentuadas de aprendizagem, utilizada na Resolução CNE/CEB no 02, é empregada, porém trata-se de um documento destinado especificamente à inclusão de alunos com autismo e não mais com condutas típicas (BRASIL, 2004).

O texto desse exemplar afirma que se configura como fonte de orientação e pesquisa para o professor da rede regular de ensino, nos casos de inclusão de alunos com autismo. A abordagem é fundamentada no método comportamental 


\footnotetext{
Atos de Pesquisa em Educação - ISSN 1809-0354

Blumenau - vol. 11, n. 2, p.374-395 ago./nov. 2016

DOI: http://dx.doi.org/10.7867/1809-0354.2016v11n2p374-395
}

Treatmente and Education os Autistic and Related Communication Handicapped Children (TEACCH), conforme exposto na introdução do documento.

Esse volume possui um caráter prescritivo e apresenta uma série de orientações que parecem uma tentativa de contemplar todas as situações que poderão ocorrer na escola. Essas prescrições dizem respeito tanto a práticas em "sala comum do ensino regular" quanto em "classe especial do ensino regular". Temos, assim, sugestões quanto à preparação dos demais alunos, às adaptações na sala de aula e no currículo e à organização da classe especial e das atividades propostas. Em seguida, o texto cita uma série de alterações do comportamento adaptativo que poderão ser observadas, como, por exemplo, choro sem causa aparente ou recusa a realizar as tarefas, que vêm acompanhadas de sugestões para evitar e, caso ocorram, enfrentar essas alterações.

Feita a apreciação desse documento, é interessante destacarmos três pontos: o primeiro é a possibilidade do trabalho pedagógico em classe especial, que não mais aparece nos documentos a partir da política de 2008; o segundo é o caráter prescritivo do texto, com ênfase na adaptação de comportamentos; e o terceiro é que, ao se tratar do autismo, parece que ainda não há uma prevalência tão significativa do discurso médico, como percebemos nas atuais políticas.

Após discorrermos sobre o uso da expressão condutas típicas para fazer referência aos sujeitos com autismo ou situá-los entre os alunos com dificuldades acentuadas de aprendizagem, analisaremos como eles são apresentados a partir da promulgação da Política Nacional de Educação Especial na Perspectiva da Educação Inclusiva (BRASIL, 2008a). É interessante ressaltar que, a partir da promulgação dessa política, os documentos da Educação Especial, aqui analisados, passaram a embasar-se em manuais médicos de classificação para fazer referência aos alunos com autismo.

A atual política de Educação Especial reafirma o direito de todos os alunos, independentemente de suas necessidades educacionais específicas, de frequentarem o ensino comum e, no contraturno, terem acesso ao atendimento educacional especializado (AEE). Além disso, esse documento define claramente quais serão os alunos atendidos pela modalidade de ensino da Educação Especial. 


\section{Atos de Pesquisa em Educação - ISSN 1809-0354 \\ Blumenau - vol. 11, n. 2, p.374-395 ago./nov. 2016 \\ DOI: http://dx.doi.org/10.7867/1809-0354.2016v11n2p374-395}

Dentre os alunos considerados público-alvo, estão os sujeitos com transtornos globais do desenvolvimento, categoria da qual faz parte o autismo. Esses sujeitos são descritos na política da seguinte forma:

Os alunos com transtornos globais do desenvolvimento são aqueles que apresentam alterações qualitativas das interações sociais recíprocas e na comunicação, um repertório de interesses e atividades restrito, estereotipado e repetitivo. Incluem-se nesse grupo alunos com autismo, síndromes do espectro do autismo e psicose infantil (BRASIL, 2008a, p. 9).

Podemos observar que, em relação ao conceito dos transtornos globais do desenvolvimento, a política usa uma definição semelhante às utilizadas no DSM-IVTR: alterações tanto na interação social quanto na comunicação e um repertório restrito, estereotipado e repetitivo de atividades e interesses.

No que tange às categorias elencadas nesses transtornos, a Política Nacional de Educação Especial na Perspectiva da Educação Inclusiva cita apenas três: autismo, síndrome do espectro do autismo e psicose infantil. Na verdade, o termo psicose infantil não consta em nenhuma das classificações oficiais citadas, o DSMIV-TR, o DSM-V e a CID-10. No DSM-IV, ocorreu a retirada dessa categoria que, na edição anterior, o DSM-III, figurava entre os transtornos mentais.

Por sua vez, a Resolução CNE/CEB no 4/2009, dispositivo normativo que se seguiu à promulgação da Política Nacional de Educação Especial na perspectiva da Educação Inclusiva (BRASIL, 2008a), traz a seguinte definição para os alunos com transtornos globais do desenvolvimento:

[...] aqueles que apresentam um quadro de alterações no desenvolvimento neuropsicomotor, comprometimento nas relações sociais, na comunicação ou estereotipias motoras. Incluem-se nessa definição alunos com autismo clássico, síndrome de Asperger, síndrome de Rett, transtorno desintegrativo da infância (psicoses) e transtornos invasivos sem outra especificação (BRASIL, 2009a).

Observamos, no fragmento acima, que a definição dos transtornos globais do desenvolvimento é modificada, acrescentando-se ,às manifestações, alterações no desenvolvimento neuropsicomotor e estereotipias motoras. Em relação às categorias, percebemos que são utilizados os cinco quadros descritos no DSM-IV- 


\section{Atos de Pesquisa em Educação - ISSN 1809-0354 \\ Blumenau - vol. 11, n. 2, p.374-395 ago./nov. 2016 \\ DOI: http://dx.doi.org/10.7867/1809-0354.2016v11n2p374-395}

TR, apesar de diferenças pouco significativas na nomeação de cada categoria. Notamos, ainda, que o termo psicose aparece entre parênteses após a categoria transtorno desintegrativo da infância.

Nosso próximo material de análise serão os Cadernos de Instruções do Censo Escolar - Educacenso, dos anos de 2007 a 2015. O censo escolar, coordenado pelo INEP, é realizado anualmente por todas as escolas de Educação Básica da rede pública e privada do país, a fim de coletar dados sobre as instituições, os alunos, os profissionais e as turmas. Dentre os dados coletados dos diretores dos estabelecimentos escolares, deverá constar o número dos alunos matriculados na modalidade de ensino da Educação Especial. Os Cadernos de Instruções do Censo Escolar - Educacenso são disponibilizados às escolas para orientar esse preenchimento. Quanto à Educação Especial, há uma parte que especifica quem são os estudantes público-alvo dessa modalidade de ensino, apresentando breves descrições de cada grupo de alunos.

A apreciação desses documentos será realizada para que possamos compreender o modo como os alunos com autismo foram designados e descritos nas orientações para o preenchimento do censo escolar. Esses cadernos foram disponibilizados a partir de 2007, ano em que o censo passou a ser coletado por meio do Sistema Educacenso (INSTITUTO NACIONAL DE ESTUDOS E PESQUISAS EDUCACIONAIS ANÍSIO TEIXEIRA, 2015).

Em 2007, ano anterior à promulgação da Política Nacional de Educação Especial na Perspectiva da Educação Inclusiva (BRASIL, 2008a), dentre os alunos que poderiam ser cadastrados na modalidade de ensino da Educação Especial, estavam os sujeitos com transtornos invasivos do desenvolvimento. Na definição desses transtornos, encontramos o seguinte texto:

\footnotetext{
Manifestações de quadros psicológicos, neurológicos, psiquiátricos ou de síndromes que ocasionam atrasos no desenvolvimento e prejuízos no relacionamento social, em grau que requeira atendimento educacional especializado (BRASIL, 2007, p. 37).
}

Através da análise desse fragmento, observamos que o termo utilizado é transtornos invasivos do desenvolvimento (CID-10); no entanto, a definição é 


\section{Atos de Pesquisa em Educação - ISSN 1809-0354 \\ Blumenau - vol. 11, n. 2, p.374-395 ago./nov. 2016 \\ DOI: http://dx.doi.org/10.7867/1809-0354.2016v11n2p374-395}

praticamente a mesma do termo condutas típicas, que consta no texto da Política Nacional de Educação Especial de 1994. Além disso, nenhuma subcategoria é elencada nessa definição.

No Caderno de Instruções do Censo Escolar de 2008, a expressão utilizada passa a ser transtornos globais do desenvolvimento (DSM-IV-TR). Porém, a definição segue a mesma e nenhuma subcategoria é ainda elencada, assim como em 2007 (BRASIL, 2008b).

Em 2009, a definição utilizada no Caderno de Instruções para os transtornos globais do desenvolvimento é a mesma da Resolução CNE/CEB № 4/2009. Pela primeira vez, são elencadas subcategorias para esses transtornos: autismo clássico, síndrome de Asperger, síndrome de Rett e transtorno desintegrativo da infância (psicoses). Inferimos que a quinta categoria que consta no DSM-IV-TR, transtorno global do desenvolvimento sem outra especificação, não se encontra entre os quadros descritos no Educacenso. No restante, as categorias são as mesmas que aparecem na Resolução CNE/CEB no 4/2009 (BRASIL, 2009a, 2009b).

Já no ano de 2010, tanto a definição quanto as subcategorias seguem as mesmas. No entanto, surge uma breve descrição de cada subcategoria (BRASIL, 2010).

No Caderno de Instruções do Censo Escolar de 2011, são realizadas duas alterações de nomenclatura nas categorias elencadas nos transtornos globais do desenvolvimento. $O$ autismo clássico passa a ser nomeado como autismo infantil e o termo psicose, que constava entre parênteses depois da categoria transtorno desintegrativo da infância, é retirado. As outras duas categorias, a síndrome de Rett e a síndrome de Asperger, seguem com a mesma nomenclatura. Em relação à definição dos transtornos globais do desenvolvimento, o texto segue o mesmo. Todavia, a descrição das categorias sofre algumas modificações (BRASIL, 2011).

Nos anos de 2012 e 2013, as orientações do Caderno de Instruções do Censo Escolar quanto aos transtornos globais do desenvolvimento não sofrem modificações quanto ao ano anterior (BRASIL, 2012, 2013b).

Em 2014, o caderno que orienta o preenchimento do censo escolar segue trazendo a categoria transtornos globais do desenvolvimento como público-alvo da 


\section{Atos de Pesquisa em Educação - ISSN 1809-0354 \\ Blumenau - vol. 11, n. 2, p.374-395 ago./nov. 2016 \\ DOI: http://dx.doi.org/10.7867/1809-0354.2016v11n2p374-395}

Educação Especial, com as quatro subcategorias definidas nos anos anteriores. Observamos apenas uma modificação em relação ao termo autismo infantil, que passa a ser designado somente por autismo. No que tange à descrição dos transtornos globais do desenvolvimento e das quatro subcategorias elencadas, houve alterações na escrita dessas definições, com exceção da síndrome de Rett, que permaneceu com o mesmo texto de caracterização (BRASIL, 2014).

Por fim, no Caderno de Instruções do Censo Escolar de 2015, as categorias seguem as mesmas do ano anterior. Em relação às definições, constatamos alterações apenas na síndrome de Rett, descrita de forma mais detalhada nesse exemplar.

Através da apreciação dos Cadernos de Instruções do Censo Escolar Educacenso, conferimos as constantes modificações e construções quanto aos termos, às definições e às subcategorias descritas na categoria dos transtornos globais do desenvolvimento, grupo de alunos considerados público-alvo da Educação Especial. É interessante ressaltar que, apesar da nova nomenclatura e classificação apresentadas pelo DSM-5 (transtorno do espectro autista) e da adoção dessa terminologia em um documento recente da Educação Especial (Nota Técnica no 24/2013/MEC/SECADI/DPEE), as categorias no Censo Escolar seguiram sem alterações.

Nosso último documento de análise, é a Nota Técnica no 24/2013/MEC/SECADI/DPEE, que orienta os Sistemas de Ensino para a implementação da Lei no 12.764 , lei que institui a Política Nacional de Proteção aos Direitos da Pessoa com Transtorno do Espectro Autista (BRASIL, 2013a). Essa nota técnica define que a pessoa com transtorno do espectro autista é considerada pessoa com deficiência para todos os efeitos legais, trazendo, em seu texto, a seguinte definição:

Pessoas com deficiência são aquelas que têm impedimentos de longo prazo de natureza física, mental, intelectual ou sensorial, os quais, em interação com as diversas barreiras, podem obstruir sua participação plena e efetiva na sociedade em igualdade de condição com as demais pessoas (ONU, 2006 apud BRASIL, 2013b). 


\section{Atos de Pesquisa em Educação - ISSN 1809-0354 \\ Blumenau - vol. 11, n. 2, p.374-395 ago./nov. 2016 \\ DOI: http://dx.doi.org/10.7867/1809-0354.2016v11n2p374-395}

Nesse documento, portanto, o sujeito com transtorno do espectro autista é considerado, com base na Lei ํㅜ 12.764, uma pessoa com deficiência (BRASIL, 2012). Dessa forma, o sujeito com autismo tem assegurados os mesmos direitos que são garantidos, na legislação, às pessoas com deficiência.

No que se refere à educação, a nota técnica assevera o direito a um sistema educacional inclusivo em todos os níveis de ensino, orientando quanto à formação inicial e continuada dos profissionais da educação. No âmbito da inclusão, o documento destaca a importância de a escolarização desses sujeitos visar à organização das atividades junto aos colegas, evitando espaços separados e horários reduzidos; da autonomia e do desenvolvimento das relações sociais; da avaliação pedagógica flexível; do estímulo à comunicação; das estratégias visuais de comunicação; da Comunicação Alternativa/Aumentativa; entre outros.

Além de assegurar 0 direito à matrícula no ensino comum, o documento afirma que deve ser garantido aos alunos com transtorno do espectro autista o AEE na escola. A presença de um profissional de apoio para esses estudantes é garantida. Esse profissional deverá ser disponibilizado pelo sistema de ensino sempre que for identificada a necessidade desse acompanhamento.

Dessa forma, percebemos que esse documento traz orientações bastante diversas sobre o trabalho pedagógico que, para a SECADI, deve ser desenvolvido com os alunos com transtorno do espectro autista nas instituições escolares. Não pretendemos, neste texto, realizar uma análise mais aprofundada dessas orientações, mas pontuar a atual nomeação do autismo, baseada no DSM-5, e o fato de a pessoa com autismo ser considerada pessoa com deficiência, o que não era afirmado nos textos dos documentos anteriores à Lei oㅜ 12.764/2012.

\section{CONSIDERAÇÕES FINAIS}

Por meio da análise de documentos da Educação Especial que versam sobre os alunos com autismo, observamos constantes alterações nas designações desses sujeitos desde 1994. Observamos, inicialmente, que as políticas públicas nacionais tratavam do autismo de forma pouco clara, utilizando a abrangente categoria das 


\section{Atos de Pesquisa em Educação - ISSN 1809-0354 \\ Blumenau - vol. 11, n. 2, p.374-395 ago./nov. 2016 \\ DOI: http://dx.doi.org/10.7867/1809-0354.2016v11n2p374-395}

condutas típicas, o que trazia como consequência o tangenciamento acerca do trabalho pedagógico com esses alunos.

Em documentos mais recentes, percebemos, além de uma ênfase mais específica no autismo, uma continuidade de alterações nas terminologias, classificações e definições. Além disso, com base na publicação da Política Nacional de Educação Especial na Perspectiva da Educação Inclusiva, em 2008, é evidenciado como o discurso médico psiquiátrico, dos manuais de classificação, é tomado como referência para designar e caracterizar o sujeito com autismo.

A análise desses documentos do campo da Educação Especial, a partir do momento histórico em que o movimento pela educação inclusiva começa a tomar mais força no país, faz-se bastante pertinente. Neste artigo, procuramos examinar a forma como os sujeitos com autismo foram nomeados e concebidos nos textos porque o que é enunciado nesses documentos produz efeitos na forma como a escola olha para esses alunos. Esse olhar, por sua vez, acaba influenciando as práticas escolares em relação a esses estudantes.

É importante salientar, ainda, que os documentos analisados orientam e direcionam as produções de políticas nas instituições escolares, as práticas pedagógicas propostas e as normas e regras estabelecidas. Ademais, possuem uma ampla circulação nas escolas que recebem os alunos com autismo.

Em relação à forma de nomear esses alunos, consideramos que, apesar das dificuldades e constantes alterações, houve um avanço significativo nas políticas públicas para os sujeitos com autismo nos últimos anos. O uso dessa terminologia nos dispositivos legais e nos documentos orientadores do MEC oportuniza pensar as especificidades da escolarização desses sujeitos, o que era mais difícil quando se utilizava a abrangente categoria das condutas típicas.

Por fim, as promulgações da Lei $n^{\circ}$ 12.764/2012 (BRASIL, 2012) e a publicação da Nota Técnica ํo 24/2013/MEC/SECADI/DPEE, considerando a pessoa com transtorno do espectro autista pessoa com deficiência são importantes no sentido de garantir direitos a esses sujeitos. No entanto, a aproximação do autismo à deficiência precisa ser problematizada, uma vez que nem sempre os sujeitos com autismo possuem uma deficiência associada. Com base nisso, 


\section{Atos de Pesquisa em Educação - ISSN 1809-0354 \\ Blumenau - vol. 11, n. 2, p.374-395 ago./nov. 2016 \\ DOI: http://dx.doi.org/10.7867/1809-0354.2016v11n2p374-395}

poderíamos pensar sobre os efeitos produzidos nas escolas quando os documentos afirmam que esses sujeitos são considerados pessoas com deficiência.

Desse modo, a análise de documentos do campo da Educação Especial, que orientam os sistemas de ensino, permitiu a discussão sobre as formas de designar o sujeito com autismo. Essas análises são importantes e poderão contribuir com reflexões sobre os investimentos no campo das políticas públicas de inclusão na contemporaneidade, bem como, criar diferentes possibilidades de escolarização para esses alunos.

\section{TAÍS GUARESCHI}

Licenciada em Educação Especial e Mestre em Educação pela Universidade Federal de Santa Maria - UFSM. Doutoranda em Educação na Universidade Federal de Santa Maria.

\section{MARCIA DORALINA ALVES}

Licenciada em Educação Especial pela Universidade Federal de Santa Maria UFSM. Graduada em Psicologia pela Pontifícia Universidade Católica do Paraná PUC/PR. Doutora em Educação pela Universidade do Vale do Rio dos Sinos UNISINOS.

\section{MARIA INÊS NAUJORKS}

Licenciada em Educação Especial pela Universidade Federal de Santa Maria UFSM. Doutora em Psicologia pelo Instituto de Psicologia da Universidade de São Paulo - USP. Professora do Departamento de Educação Especial, do Centro de Educação, da Universidade Federal de Santa Maria. Docente credenciada no Programa de Pós Graduação em Educação - PPGE/UFSM.

\section{REFERÊNCIAS}

ASSOCIAÇÃO AMERICANA DE PSIQUIATRIA. DSM-IV-TR: Manual diagnóstico e estatístico de transtornos mentais. 4. ed. rev. Porto Alegre: Artmed, 2002.

ASSOCIAÇÃO AMERICANA DE PSIQUIATRIA (APA). DSM-V: manual de diagnóstico e estatístico de transtornos mentais. Tradução: Maria Inês Corrêa Nascimento et al. 5. ed. Porto Alegre: Artmed, 2014.

BRASIL. Declaração de Salamanca e linha de ação sobre necessidades educativas especiais. Brasília: UNESCO, 1994a. 


\author{
Atos de Pesquisa em Educação - ISSN 1809-0354 \\ Blumenau - vol. 11, n. 2, p.374-395 ago./nov. 2016 \\ DOI: http://dx.doi.org/10.7867/1809-0354.2016v11n2p374-395
}

BRASIL. Política Nacional de Educação Especial: livro 1. Brasília: MEC/SEESP, 1994b.

BRASIL. Resolução CNE/CEB no 02 de 11 de setembro de 2001. Institui Diretrizes Nacionais para Educação Especial na Educação Básica. Diário Oficial da República Federativa do Brasil, Brasília, DF, n. 177, p. 39-40, 14 set. 2001. Seção 1E.

BRASIL. Projeto Escola Viva - Garantindo o acesso e permanência de todos os alunos na escola - Alunos com necessidades educacionais especiais:

Reconhecendo os alunos que apresentam dificuldades acentuadas de

aprendizagem, relacionadas a condutas típicas. Brasília: MEC/SEESP, 2002.

BRASIL. Saberes e práticas da inclusão: dificuldades acentuadas de aprendizagem: autismo. Brasília: MEC/SEESP, 2004.

BRASIL. Documento subsidiário à política de inclusão. Brasília: MEC/SEESP, 2005.

BRASIL. Censo Escolar 2007 - Educacenso: Caderno de Instruções. Brasília: MEC/INEP, 2007.

BRASIL. Política Nacional de Educação Especial na perspectiva da Educação Inclusiva. Brasília: MEC/SEESP, 2008a.

BRASIL. Censo Escolar 2008 - Educacenso: Caderno de Instruções. Brasília: MEC/INEP, 2008b.

BRASIL. Resolução CNE/CEB no 4/2009. Institui Diretrizes Operacionais para o Atendimento Educacional Especializado na Educação Básica, modalidade Educação Especial. Diário Oficial da República Federativa do Brasil, Brasília, DF, n. 190, p. 17, 05 out. 2009a. Seção 1.

BRASIL. Censo Escolar 2009 - Educacenso: Caderno de Instruções. Brasília: MEC/INEP, 2009b.

BRASIL. Censo Escolar 2010 - Educacenso: Caderno de Instruções. Brasília: MEC/INEP, 2010.

BRASIL. Censo Escolar 2011 - Educacenso: Caderno de Instruções. Brasília: MEC/INEP, 2011.

BRASIL. Censo Escolar 2012 - Educacenso: Caderno de Instruções. Brasília: MEC/INEP, 2012.

BRASIL. Lei no 12.764 de 27 de dezembro de 2012. Institui a Política Nacional de Proteção dos Direitos da Pessoa com Transtornos do Espectro Autista; e altera o 3 o 


\section{Atos de Pesquisa em Educação - ISSN 1809-0354 \\ Blumenau - vol. 11, n. 2, p.374-395 ago./nov. 2016 \\ DOI: http://dx.doi.org/10.7867/1809-0354.2016v11n2p374-395}

do art. 98 da Lei no 8.112, de 11 de dezembro de 1990. Diário Oficial da República Federativa do Brasil, Brasília, DF, n. 250, p. 02, 28 dez. 2012. Seção 1.

BRASIL. Nota Técnica no24/2013/MEC/SECADI/DPE. Orientação aos Sistemas de Ensino para a implementação da Lei oㅜ 12.764/2012. Brasília: MEC/SECADI/DPEE, 2013a.

BRASIL. Censo Escolar 2013 - Educacenso: Caderno de Instruções. Brasília: MEC/INEP, 2013b.

BRASIL. Censo Escolar 2014 - Educacenso: Caderno de Instruções. Brasília: MEC/INEP, 2014.

BRASIL. Censo Escolar 2015 - Educacenso: Caderno de Instruções. Brasília: MEC/INEP, 2015.

INSTITUTO NACIONAL DE ESTUDOS E PESQUISAS EDUCACIONAIS ANÍSIO TEIXEIRA (INEP). Formulários e Cadernos de Instruções. Disponível em: <http://portal.inep.gov.br/basica-censo/formularios-e-cadernos-de-instrucoes> Acesso em: 20 jun. 2015.

ORGANIZAÇÃO MUNDIAL DE SAÚDE (Coord.). Classificação de Transtornos Mentais e de Comportamento da CID-10: descrições clínicas e diretrizes diagnósticas. Porto Alegre: Artes Médicas, 1993.

ROCHA, M. M.; COSTA, M. da P. R. da. Condutas típicas na Educação Especial: histórico, conceituação vigente e TDAH. In: COSTA, M. da P.R.da. (Org.). Educação Especial: aspectos conceituais e emergentes. São Carlos: EdUFSCar, 2009, p.6382.

SIBEMBERG, N. Atenção com o diagnóstico: a suspeita de autismo nem sempre se confirma. In: JERUSALINSKY, A. (Org.). Dossiê autismo. São Paulo: Instituto Langage, 2015, p. 94-105.

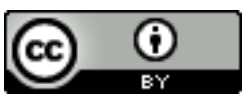

Este trabalho está licenciado com uma Licença Creative Commons - Atribuição 4.0 Internacional 